\title{
Assessment of urinary biomarkers of mycotoxin exposure in adults from Cameroon
}

\section{Wilfred Angie Abia ( $\square$ abiawilfred@yahoo.com )}

Universite de Yaounde I https://orcid.org/0000-0003-3796-8616

Angele N. Tchana

Universite de Yaounde I

Doumani Djonabaye

Universite de Yaounde I

\section{Bojan Šarkanj}

university of north croatia

\section{Euloge Yiagnigni Mfopou}

clinique les promoteurs de la bonne sante Yaounde Cameroon

Chibundu N. Ezekiel

Babcock University, Ilishan Nigeria

\section{Micheal Sulyok}

university of natural resources and life sciences, vienna boku-ifa Austria

\section{Paul C. Turner}

MIAEH University of Maryland USA

\section{Christopher T. Elliott}

IGFS, Biological Sciences, Queens University Belfast

\section{Benedikt Warth}

University of Vienna

\section{Rudolf Krska}

University of Natural Resources and life sciences, Vienna IFA-BOKU Austria

\section{Paul F. Moundipa}

Universite de Yaounde I

\section{Research}

Keywords: Cameroon, Mycotoxin exposures, Urinary biomarkers, Human Biomonitoring, LC-MS/MS

Posted Date: June 1st, 2020

DOI: https://doi.org/10.21203/rs.3.rs-31062/v1 
License: (c) (i) This work is licensed under a Creative Commons Attribution 4.0 International License. Read Full License 


\section{Abstract \\ Background}

In Cameroon dietary staples are contaminated with diverse toxic fungal metabolites, known as mycotoxins. Aflatoxins and fumonisins are of particular public health concern, particularly in relation to cancer and/or early life stunting. Mixtures of these toxins are predicted from food measures, and in this work, the levels and frequencies of urinary mycotoxin biomarkers are reported in Cameroonian adults.

\section{Methods}

A single first void urine sample was collected from 89 adults (aged range: $28-85$, male 39 , female 50) from the city of Yaoundé, Centre Region, Cameroon. Urines were tested for eight distinct mycotoxins using measures of both parent compounds and/or their metabolites by Liquid Chromatography tandem mass spectrometry (LC-MS/MS).

\section{Results}

Altogether seven distinct mycotoxins, aflatoxin, fumonisin, deoxynivalenol, zearalenone, nivalenol, ochratoxin A and citrinin, (or their metabolites) were observed in urine samples. At least one mycotoxin was detected in all of the urine samples, $87(97.8 \%)$ of which were above the method's quantification limit. Aflatoxin $\mathrm{M}_{1}$ was detected in $42 \%$ (n.d. $-0.21 \mu \mathrm{L} \mathrm{L}^{-1}$ ) of samples of which about a quarter additionally contained fumonisin $B_{1}$. Of the remaining toxins deoxynivalenol, zearalenone, ochratoxin $A$, nivalenol and citrinin were present in $78 \%, 99 \% 95 \%, 53 \%$, and $87 \%$ of the samples respectively. Alternariol was not detected in any sample. Mixtures of mycotoxins in the samples were frequently observed with 64 samples $(72 \%)$ containing more than five mycotoxins. Estimates of intake exceeded the TDIs for fumonisin $(n=4)$, deoxynivalenol $(n=1)$ and zearalenone $(n=2)$, no TDI is set for aflatoxin.

\section{Conclusions}

This study reveals frequent co-exposure of Cameroonian individuals to a complex mixture of toxic and carcinogenic mycotoxins, with mixtures of aflatoxin and fumonisin a particular priority from a public health standpoint.

\section{Background}

Foodstuffs around the world are frequently contaminated during crop growth and/or storage by several toxigenic fungi that produce poisonous secondary metabolites, known as mycotoxins. Poor agricultural techniques, under favourable conditions including temperature and relative humidity often exacerbate 
toxin production in many world regions [1, 2]. In sub-Saharan Africa, poor and prolonged storage additionally contribute to the burden of crop contamination for some mycotoxins, such as aflatoxins. Many mycotoxins are heat resistant, such that traditional cooking practices with grains or nuts have little impact on plate-ready concentrations $[3,4]$. Consequently, mycotoxin exposure seems inevitable in many parts of rural Africa.

Acute and chronic ingestion of mycotoxins can be harmful to health, and on occasions be fatal [5]. Mycotoxins such as aflatoxin $B_{1}\left(A_{F B}\right)$ are proven human carcinogens [6]. Additionally, $\mathrm{AFB}_{1}$ and other mycotoxins are implicated in a range of other conditions including kwashiorkor in children [7], infant stunting $\left(\mathrm{AFB}_{1}\right.$ and fumonisin $\left.\mathrm{B}_{1}, \mathrm{FB}_{1}\right)[8,9,10]$, immunosuppression ( $\mathrm{AFB}_{1}$ and deoxynivalenol, $\left.\mathrm{DON}\right)$ $[11,12,13,14,15]$, and neural tube defects $\left(\mathrm{FB}_{1}\right)[16,17]$. The diversity of these health effects creates significant concerns regarding the need to monitor and assess the potential risks posed to consumers of mycotoxin-tainted foods in regions where mycotoxin-prone crops are frequently consumed [8]. Maximum tolerable limits (MTLs) in food for some mycotoxins such as aflatoxins ( $\mathrm{AFB}_{1}$, and total $A F s$ ), fumonisins $\left(\mathrm{FB}_{1}\right.$, and total $\left.\mathrm{FBs}\right)$, ochratoxin $\mathrm{A}(\mathrm{OTA})$, deoxynivalenol (DON), and zearalenone (ZEN) have been established $[18,19,20,21]$. Tolerable daily intake (TDI) levels for some of the frequently occurring toxins including $\mathrm{FB}_{1}$ has also been defined by the Scientific Committee on Food [22] and DON by the European Food Safety Agency[23], likewise ZEN [24]; but as a proven carcinogen, no recommended TDI is possible for $\mathrm{AFB}_{1}$.

In Cameroon, reports on mycotoxin contamination of raw and cooked foods are increasing in the past decade $[7,25,26,2728,29]$. $\mathrm{AFB}_{1}$ and $\mathrm{FB}_{1}$ have been observed in food, and in some cases the concentrations exceeded MTLs stipulated by the Codex Alimentarius [18] and the European Union [20]. Limited data are available that measure multiple urinary markers of mycotoxin in exposure in Cameroon, including 175 adults [30] and 220 young children [28]. Here we report data from 89 Cameroon adults by a highly sensitive LC-MS/MS method to add to the growing data sets on individual mycotoxin measurements in Sub-Saharan Africa.

\section{Materials And Methods}

\section{Study populations, recruitment of participants and sample collection}

This study was carried out in 2013 in the city of Yaoundé, Centre Region, Cameroon. Targeted subpopulations were informed about the nature of the study. Signed informed consent forms were obtained from 89 adult male $(n=39)$ and female $(n=50)$ volunteers (age range: $28-85$ years, body weight (range: 55-129 kg)) recruited in this study. Ethical approval was received from the Cameroon National Ethics Committee of Research for Human Health (Authorisation No. 2013/05/252/CNERSH/SP). First morning urine samples ( $50 \mathrm{~mL}$ each) were collected from each recruited individual in sealed mailing urine bottles. The urine samples were immediately frozen and transported on dry ice to BOKU/IFA-Tulln, Austria, where 
they were stored at $-20^{\circ} \mathrm{C}$ until analysis. Sixty-six of the participants were part of a hypertension clinic in Yaounde (Les Promoteurs de la Bonne Sante). Additional data on age, weight, height or body mass index (BMI) of the hypertensive versus non hypertensive participants are provided in Supplementary Table S1.

\section{Reagents and Chemicals}

Methanol (MeOH; LC gradient grade), acetonitrile (ACN; LC gradient grade), and glacial acetic acid (HAc; MS grade) were purchased from Merck (Darmstadt, Germany). Mycotoxin standards were purchased from Romer Labs Diagnostic GmbH Tulln, Austria, including: nivalenol (NIV), ${ }^{13} \mathrm{C}-\mathrm{NIV}, \mathrm{DON},{ }^{13} \mathrm{C}-\mathrm{DON}$, deepoxy-DON (DOM-1), OTA, ${ }^{13} \mathrm{C}-\mathrm{OTA}, \mathrm{AFM}_{1},{ }^{13} \mathrm{C}-\mathrm{AFM} \mathrm{A}_{1}$, citrinin (CIT), FB $1,{ }^{13} \mathrm{C}-\mathrm{FB}_{1},{ }^{13} \mathrm{C}-\mathrm{ZEN}$ or Sigma, Vienna, Austria (ZEN, a- and $\beta$-zearalenol (ZEL)). The deuterated $\left[{ }^{2} \mathrm{H}_{4}\right]$ alternariol $(\mathrm{AOH})$ was synthesized by [31] and kindly provided by Prof. Michael Rychlik, TU Munich. Solid standard substances were dissolved in pure ACN ( $\alpha$ - and $\beta-Z E L ; ~\left[{ }^{2} \mathrm{H}_{4}\right] \mathrm{AOH}$ ). All other standards were delivered in either ACN or $\mathrm{ACN} / \mathrm{H}_{2} \mathrm{O}\left(\mathrm{FB}_{1}\right)$ and stored at $-20^{\circ} \mathrm{C}$. A combined multi-standard working solution for preparation of calibrants and spiking experiments was prepared in $\mathrm{ACN}$, and also, fresh mixture of ${ }^{13} \mathrm{C}$ and deuterated $\left[{ }^{2} \mathrm{H}_{4}\right]$ stable isotope standards were prepared as described by [32].

\section{Sample Preparation}

Urine samples were allowed to reach room temperature, and centrifuged for $3 \mathrm{~min}$ at $5600 \times \mathrm{g}$. The supernatant $(500 \mu \mathrm{L})$ was incubated with $500 \mu \mathrm{L}$ PBS $(200 \mathrm{mM}, \mathrm{pH}=7.4)$ containing $3000 \mathrm{U}$ of $\beta$ glucuronidase from E. coli Type IX-A (Sigma-Aldrich, G7396-2MU) (modified from [33]) for $16 \mathrm{~h}$ at $37^{\circ} \mathrm{C}$ to allow de-glucuronidation of mycotoxin-glucuronides (e.g. DON-15-glucuronide, ZEN-14-glucuronide [34]). Following hydrolysis, $1 \mathrm{~mL}$ was passed through Oasis PRiME HLB® SPE columns (Waters, Milford, MA), pre-equilibrated with $1 \mathrm{~mL} \mathrm{MeOH}$, and then $1 \mathrm{~mL} \mathrm{H} \mathrm{H}_{2} \mathrm{O}$. After washing twice with $500 \mu \mathrm{L} \mathrm{H}_{2} \mathrm{O}$, mycotoxins were eluted with $200 \mu \mathrm{L} \mathrm{ACN}$, three times. Extracts were evaporated under nitrogen at room temperature, reconstituted with $470 \mu \mathrm{L}$ dilution solvent $(10 \% \mathrm{ACN}, 0.1 \% \mathrm{HAc})$ and fortified with $30 \mu \mathrm{L}$ of the IS mixture as described by [32].

\section{Analysis of urine samples by liquid chromatography- electrospray ionization-tandem mass spectrometry (LC- ESI-MS/MS)}

Sample analysis was performed using a Sciex QTrap ${ }^{\circledR} 6500$ + LC-MS/MS system (Foster City, CA) equipped with a Turbo $V$ electro spray ionization (ESI) source interfaced with an Agilent 1290 series Ultrahigh performance liquid chromatography (UHPLC) system (Waldbronn, Germany) following the method described by [32] to quantify urinary mycotoxins biomarkers (UMBs) and biomeasures. In brief, analytes of interest were separated on an AtlantisT3 HSS column $(2.1 \times 100 \mathrm{~mm}$; Waters, Wexford, Ireland) with $1.8 \mu \mathrm{m}$ particle size. Eluent A (water) and eluent B (ACN) were both acidified with $0.1 \%$ HAc. After an initial period of 2 min at $90 \%$, the percentage of $B$ was linearly raised to $50 \%$ until minute 15 . Then, 
eluent $B$ was raised to $95 \%$ until min 18 followed by a hold-time of 4 min and subsequent 3 min column re-equilibration at $90 \% \mathrm{~A}$. The flow rate was set to $100 \mu \mathrm{L} \mathrm{min}{ }^{-1}$. After injection of $10 \mu \mathrm{L}$ the needle was washed for $20 \mathrm{sec}$ to minimize carry-over. The column effluent was transferred either to the mass spectrometer (minutes 5 to 22.5) or to the waste via a six-port valve. The analytes were separated on column at $35^{\circ} \mathrm{C}$.

ESI-MS/MS was performed in scheduled multiple reaction monitoring (sMRM) mode, with a $180 \mathrm{sec}$ detection windows. At least two individual transitions were monitored for each analyte. One chromatographic run consisted of two MS/MS experiments where both ionization modes run simultaneously using fast polarity switching. All measurements were conducted using: source temperature $550{ }^{\circ} \mathrm{C}$, curtain gas $30 \mathrm{psi}(69 \mathrm{kPa}$ of max. $99.5 \%$ nitrogen), ion source gas 1 (sheath gas) 80 psi (345 kPa of nitrogen), ion source gas 2 (drying gas) 80 psi (345 kPa of nitrogen), collision gas (nitrogen) high. lon spray voltage was $-4500 \mathrm{~V}$ in negative mode while it was set to $4500 \mathrm{~V}$ in positive mode.

\section{Analysis of creatinine in urine samples}

The concentration of urinary creatinine was determined on the same instrument by the rapid method described in [32]. Urinary mycotoxin concentrations were adjusted for creatinine and expressed as microgram of analyte per gram $\left(\mu \mathrm{g} \mathrm{g}^{-1}\right)$ creatinine.

\section{Statistical analysis}

Statistical analysis was performed using GraphPad In Stat version 3.10 for windows (GraphPad Software Inc, San Diego, California, USA) and Microsoft Office Excel 2010 (Part of Microsoft Professional Edition, Computer Program), Statistica 13.3. (TibcoSoft, Palo Alto, California, USA). For comparisons between (sex) groups, the Mann Whitney $U$ test was used since the data is not normally distributed (tested by Shapiro-Wilk's W test).

\section{Results}

There were no differences by hypertensive status in the age, weight, height or BMI of the participants (see supplement Table S1). In Table 1 basic anthropometric parameters are provided for all study participants.

Table 1

Anthropometric measures of the studied population, $n=89$

\begin{tabular}{|ll|}
\hline & Participants $(\mathbf{N}=89)$ \\
\hline Age: mean (range) year & $55.4(28.0-85.0)$ \\
\hline Weight: mean (range) kg & $84.1(55.0-129.0)$ \\
\hline Height: mean (range) $\mathrm{m}$ & $1.7(1.5-1.8)$ \\
\hline Body mass index (BMI): mean (range) $\mathrm{kg} / \mathrm{m}^{2}$ & $30.2(20.3-54.4)$ \\
\hline
\end{tabular}


Mycotoxin concentrations were measured in urine samples from 89 adult Cameroonians (males, 39 and females, 50). The LC-MS/MS method measured seven parent mycotoxins and five mycotoxin metabolites in the samples, limit of quantitation (LOQ) and limit of detection (LOD) values vary for each toxin and metabolite. The parent mycotoxins were FB 1, OTA, DON, ZEN, NIV, CIT, and AOH, whilst AFM 1 (from AFB 1 ), DOM-1 (from DON), a-ZEL and $\beta$ ZEL (from ZEN), and DHC (from CIT) constituted the metabolic products. One or more of the mycotoxins or metabolites was observed in all 89 samples, with $87 / 89$ samples having at least one of the toxins at a concentration above the LOQ (Table 2). AOH was not detected in any of the urine samples. AFM 1 was observed above the LOQ in $42 \%$ of samples (LOQ $0.001 \mu \mathrm{g} \mathrm{L}^{-1}$ : overall range n.d. $-0.210 \mu \mathrm{g} \mathrm{L}^{-1}$ ), and $\mathrm{FB}_{1}$ was observed above the LOQ in $10 \%$ of samples (LOQ $0.15 \mu \mathrm{g}$ $\mathrm{L}^{-1}$ : overall range n.d. $\left.-0.83 \mu \mathrm{g} \mathrm{L}^{-1}\right)$. Of the other mycotoxins, total DON (72\%), total CIT (80\%), OTA (80\%) and total ZEN (82\%) were observed most frequently above the LOQs, see Table 2. 
Table 2

Profiles of urinary mycotoxins biomarkers and their derivatives in 89 urine samples from Cameroon.

\begin{tabular}{|c|c|c|c|c|c|c|}
\hline \multirow[t]{2}{*}{ Analyte } & \multicolumn{6}{|c|}{ All studied participants $(\mathrm{N}=89)$} \\
\hline & $\begin{array}{l}\text { LOD } \\
\text { LOQ } \\
\left(\mu \mathrm{g} \mathrm{L}^{-}\right. \\
\left.{ }^{1}\right)\end{array}$ & $\begin{array}{l}\text { Mean } \\
(\mathrm{SD})(\mu \mathrm{g} \mathrm{L} \\
\left.{ }^{1}\right)\end{array}$ & $\begin{array}{l}\text { MedianP } \\
\text { (IQR) } \\
\left(\mu \mathrm{g} \mathrm{L}^{-1}\right)\end{array}$ & $\begin{array}{l}n> \\
\text { LOD }\end{array}$ & $\begin{array}{l}\text { n> } \\
\text { LOQ }\end{array}$ & $\begin{array}{l}\begin{array}{l}\text { *Mean } \\
(\max ) \\
\left(\mu g L^{-}\right. \\
\left.{ }^{1}\right)\end{array} \\
\end{array}$ \\
\hline $\begin{array}{l}\text { Aflatoxin } \mathrm{M}_{1} \\
\left(\mathrm{AFM}_{1}\right)\end{array}$ & $\begin{array}{l}0.0005 \\
0.001\end{array}$ & $0.03(0.05)$ & $\begin{array}{l}0.01 \\
(0.01- \\
0.03)\end{array}$ & $\begin{array}{l}37 \\
(42 \%)\end{array}$ & $\begin{array}{l}37 \\
(42 \%)\end{array}$ & $\begin{array}{l}0.01 \\
(0.21)\end{array}$ \\
\hline Fumonisin $\mathrm{B}_{1}\left(\mathrm{FB}_{1}\right)$ & $\begin{array}{l}0.05 \\
0.15\end{array}$ & $0.43(0.22)$ & $\begin{array}{l}0.35 \\
(0.24- \\
0.49)\end{array}$ & $\begin{array}{l}25 \\
(28 \%)\end{array}$ & $\begin{array}{l}9 \\
(10 \%)\end{array}$ & $\begin{array}{l}0.08 \\
(0.83)\end{array}$ \\
\hline $\begin{array}{l}\text { Deoxynivalenol } \\
\text { (DON) }\end{array}$ & $\begin{array}{l}0.05 \\
0.15\end{array}$ & $15.9(94.4)$ & $\begin{array}{l}1.91 \\
(1.21- \\
5.91)\end{array}$ & $\begin{array}{l}67 \\
(75 \%)\end{array}$ & $\begin{array}{l}64 \\
(72 \%)\end{array}$ & $\begin{array}{l}11.5 \\
(759)\end{array}$ \\
\hline $\begin{array}{l}\text { Deepoxy- } \\
\text { deoxynivalenol } \\
\text { (DOM-1) }\end{array}$ & $\begin{array}{l}0.05 \\
0.15\end{array}$ & $4.5(8.3)$ & $\begin{array}{l}1.25 \\
(0.76- \\
2.07)\end{array}$ & $\begin{array}{l}15 \\
(17 \%)\end{array}$ & $\begin{array}{l}13 \\
(15 \%)\end{array}$ & $\begin{array}{l}0.67 \\
(27.4)\end{array}$ \\
\hline $\begin{array}{l}\text { Total DON i.e. } \\
\sum(\text { DON + DOM-1) }\end{array}$ & - & $17.8(80.4)$ & $\begin{array}{l}1.38 \\
(0.29- \\
5.16)\end{array}$ & $\begin{array}{l}72 \\
(78 \%)\end{array}$ & $\begin{array}{l}68 \\
(76 \%)\end{array}$ & $\begin{array}{l}12.1 \\
(760)\end{array}$ \\
\hline Zearalenone (ZEN) & $\begin{array}{l}0.001 \\
0.003\end{array}$ & $0.16(0.21)$ & $\begin{array}{l}0.08 \\
(0.05- \\
0.18)\end{array}$ & $\begin{array}{l}86 \\
(97 \%)\end{array}$ & $\begin{array}{l}71 \\
(80 \%)\end{array}$ & $\begin{array}{l}0.13 \\
(1.10)\end{array}$ \\
\hline $\begin{array}{l}\text { Alpha-Zearalenol (a- } \\
\text { ZEL) }\end{array}$ & $\begin{array}{l}0.001 \\
0.003\end{array}$ & $0.58(0.76)$ & $\begin{array}{l}0.33 \\
(0.09- \\
0.82)\end{array}$ & $\begin{array}{l}4 \\
(5 \%)\end{array}$ & $\begin{array}{l}4 \\
(5 \%)\end{array}$ & $\begin{array}{l}0.03 \\
(1.67)\end{array}$ \\
\hline $\begin{array}{l}\text { Beta-Zearalenol ( } \beta \text { - } \\
\text { ZEL) }\end{array}$ & $\begin{array}{l}0.001 \\
0.003\end{array}$ & $0.30(0.13)$ & $\begin{array}{l}0.32 \\
(0.22- \\
0.40)\end{array}$ & $\begin{array}{l}6 \\
(7 \%)\end{array}$ & $\begin{array}{l}4 \\
(5 \%)\end{array}$ & $\begin{array}{l}0.01 \\
(0.42)\end{array}$ \\
\hline $\begin{array}{l}\text { Total ZEN i.e. } \\
\sum(Z E N+\alpha-+\beta-Z E L)\end{array}$ & - & $0.17(0.31)$ & $\begin{array}{l}0.07 \\
(0.02- \\
0.16)\end{array}$ & $\begin{array}{l}88 \\
(99 \%)\end{array}$ & $\begin{array}{l}73 \\
(82 \%)\end{array}$ & $\begin{array}{l}0.17 \\
(1.67)\end{array}$ \\
\hline Ochratoxin A (OTA) & $\begin{array}{l}0.0003 \\
0.001\end{array}$ & $0.01(0.01)$ & $\begin{array}{l}0.004 \\
(0.002- \\
0.008)\end{array}$ & $\begin{array}{l}84 \\
(95 \%)\end{array}$ & $\begin{array}{l}71 \\
(80 \%)\end{array}$ & $\begin{array}{l}0.006 \\
(0.090)\end{array}$ \\
\hline
\end{tabular}

LOD: limit of detection; LOQ: limit of quantitation; Mean ${ }^{\mathbf{p}}$ : mean of samples > LOQ; Median? ${ }^{\mathbf{P}}$ : median of samples > LOQ; SD: Standard Deviation; IQR: Interquartile range; Max: Maximum; \%: Percentage; nd: Not detected; *Mean (max): Mean (maximum) all samples - values calculated with half LOD values used for samples $<$ LOD and half LOQ used for values $<$ LOQ. 


\begin{tabular}{|c|c|c|c|c|c|c|}
\hline \multirow[t]{2}{*}{ Analyte } & \multicolumn{6}{|c|}{ All studied participants $(\mathrm{N}=89)$} \\
\hline & $\begin{array}{l}\text { LOD } \\
\text { LOQ } \\
\left(\mu \mathrm{L}^{-}\right. \\
\left.{ }^{1}\right)\end{array}$ & $\begin{array}{l}\text { Mean }^{p} \\
(S D)\left(\mu g L^{-}\right. \\
\left.{ }^{1}\right)\end{array}$ & $\begin{array}{l}\text { Medianp } \\
(\text { IQR) } \\
\left(\mu \mathrm{g} \mathrm{L}^{-1}\right)\end{array}$ & $\begin{array}{l}n> \\
\text { LOD }\end{array}$ & LOQ & $\begin{array}{l}\text { *Mean } \\
(\max ) \\
\left(\mu g L^{-}\right. \\
\left.{ }^{1}\right)\end{array}$ \\
\hline Nivalenol (NIV) & $\begin{array}{l}0.033 \\
0.10\end{array}$ & $0.59(0.79)$ & $\begin{array}{l}0.33 \\
(0.19- \\
0.77)\end{array}$ & $\begin{array}{l}47 \\
(53 \%)\end{array}$ & $\begin{array}{l}32 \\
(36 \%)\end{array}$ & $\begin{array}{l}0.23 \\
(4.36)\end{array}$ \\
\hline Citrinin (CIT) & $\begin{array}{l}0.01 \\
0.03\end{array}$ & $0.28(0.39)$ & $\begin{array}{l}0.14 \\
(0.06- \\
0.33)\end{array}$ & $\begin{array}{l}66 \\
(74 \%)\end{array}$ & $\begin{array}{l}51 \\
(57 \%)\end{array}$ & $\begin{array}{l}0.16 \\
(2.15)\end{array}$ \\
\hline $\begin{array}{l}\text { Dihydrocitrinone } \\
\text { (DHC) }\end{array}$ & $\begin{array}{l}0.003 \\
0.01\end{array}$ & $2.1(12.0)$ & $\begin{array}{l}0.40 \\
(0.19- \\
0.73)\end{array}$ & $\begin{array}{l}63 \\
(71 \%)\end{array}$ & $\begin{array}{l}63 \\
(71 \%)\end{array}$ & $\begin{array}{l}1.5 \\
(96)\end{array}$ \\
\hline $\begin{array}{l}\text { Total CIT i.e. } \sum \text { (CIT } \\
+ \text { DHC) }\end{array}$ & - & 2.3 (10.3) & $\begin{array}{l}0.24 \\
(0.05- \\
0.73)\end{array}$ & $\begin{array}{l}77 \\
(87 \%)\end{array}$ & $\begin{array}{l}71 \\
(80 \%)\end{array}$ & $\begin{array}{l}1.66 \\
(97.5)\end{array}$ \\
\hline \multicolumn{7}{|c|}{$\begin{array}{l}\text { LOD: limit of detection; LOQ: limit of quantitation; Mean }{ }^{\mathrm{p}} \text { : mean of samples > LOQ; Medianp: median } \\
\text { of samples > LOQ; SD: Standard Deviation; IQR: Interquartile range; Max: Maximum; \%: Percentage; nd: } \\
\text { Not detected; *Mean (max): Mean (maximum) all samples - values calculated with half LOD values } \\
\text { used for samples < LOD and half LOQ used for values < LOQ. }\end{array}$} \\
\hline
\end{tabular}

The co-existence of mycotoxins was observed in human urine samples from Cameroon. A total of 88 (98.9\%) of the 89 studied urine samples had two or more mycotoxins at detectable concentrations (Table 3). Altogether, 20 different patterns of urinary mycotoxin mixtures were observed. The majority (64; $72 \%$ ) of the 89 studied urine samples contained five to seven different mycotoxin combinations constituting 10 of the 20 observed patterns. $A_{F M}$ was in 9/20 different mixture combinations of urinary mycotoxins, including six combinations where urine contained five or more toxins. $\mathrm{AFM}_{1}$ and $\mathrm{FB}_{1}$ were co-observed in three distinct urinary mixtures. ZEN (19/20,95\%) and OTA (19/20; 95\%) were the most frequent mycotoxins represented in the mixtures, while $\mathrm{FB}_{1}$ was the least $(7 / 20,35 \%)$, see Table 3 . 
Table 3

Mycotoxin mixtures in 89 urine samples from Cameroon

\begin{tabular}{|c|c|c|c|c|c|c|c|c|}
\hline \multirow{2}{*}{$\begin{array}{l}\text { No. of } \\
\text { mycotoxins }\end{array}$} & \multicolumn{7}{|c|}{ Mycotoxins mixture types } & \multirow[t]{2}{*}{ Frequency } \\
\hline & $\mathrm{AFM}_{1}$ & $\mathrm{FB}_{1}$ & DON & ZEN & OTA & NIV & CIT & \\
\hline 7 & + & + & + & + & + & + & + & $6(6.7 \%)$ \\
\hline \multirow[t]{3}{*}{6} & + & - & + & + & + & + & + & $10(11.2 \%)$ \\
\hline & + & + & + & + & + & - & + & $2(2.2 \%)$ \\
\hline & - & + & + & + & + & + & + & $11(12.4 \%)$ \\
\hline \multirow[t]{6}{*}{5} & + & + & + & + & + & - & - & $1(1.1 \%)$ \\
\hline & + & - & - & + & + & + & + & $3(3.4 \%)$ \\
\hline & + & - & + & + & + & - & + & $11(12.4 \%)$ \\
\hline & - & + & - & + & + & + & + & $4(4.5 \%)$ \\
\hline & - & + & + & + & + & - & + & $3(3.4 \%)$ \\
\hline & - & - & + & + & + & + & + & $13(14.6 \%)$ \\
\hline \multirow[t]{6}{*}{4} & + & - & - & + & + & + & - & $1(1.1 \%)$ \\
\hline & + & - & - & + & + & - & + & $2(2.2 \%)$ \\
\hline & - & + & - & + & + & - & + & $1(1.1 \%)$ \\
\hline & - & - & + & + & + & - & + & $14(15.7 \%)$ \\
\hline & - & - & - & + & + & + & + & $1(1.1 \%)$ \\
\hline & - & - & + & + & + & + & - & $1(1.1 \%)$ \\
\hline \multirow[t]{3}{*}{3} & + & - & - & - & + & - & + & $1(1.1 \%)$ \\
\hline & - & - & - & + & + & - & + & $2(2.2 \%)$ \\
\hline & - & - & - & + & + & + & - & $1(1.1 \%)$ \\
\hline 2 & - & - & - & + & - & - & + & $1(1.1 \%)$ \\
\hline Occurrence $(n=20)$ & 9 & 7 & 10 & 19 & 19 & 10 & 16 & \\
\hline$\%$ & 45 & 35 & 50 & 95 & 95 & 50 & 80 & \\
\hline
\end{tabular}

Intakes of each mycotoxin can be roughly estimated using the individual mycotoxin concentration (including parent and metabolites), an estimated average urinary output of 1.5 litre per day, mean estimates of transfer of the mycotoxins from the diet to urine, and individual bodyweight. In Table 4 the mean estimated intakes are compared to established TDIs for four mycotoxins where the transfer 
percentage has been established. There is no TDI for aflatoxins, and the overall mean estimated intake for $F_{1}, D_{0 N}$ and $Z E N$ did not exceed the TDI. A few individuals were predicted to exceed the TDI for FB 1 (4/89), DON (1/89) and ZEN (2/89). No individuals exceeded the TDI for more than one mycotoxin. Individuals with the maximum estimated intake were $2.95,17.6$ and 1.92 times higher than the TDI for $\mathrm{FB}_{1}, \mathrm{DON}$ and ZEN, respectively. Using linear regression there were no significant relationships between estimated intakes for any of the four mycotoxins, data not shown.

Table 4

Intake estimates based on urinary mycotoxin concentrations.

\begin{tabular}{|c|c|c|c|c|}
\hline & Aflatoxin & Fumonisin & Deoxynivalenol & Zearalenone \\
\hline Urinary excretion rate [\%] & $1-3^{a}$ & $0.3^{b}$ & $72^{c}$ & $9.4^{d}$ \\
\hline \#Intake Mean (SD) $\left[\mu \mathrm{g} \mathrm{kg}^{-1} \mathrm{bw} / \mathrm{d}\right]$ & $0.007(0.02)$ & $0.44(0.86)$ & $0.29(1.86)$ & $0.034(0.07)$ \\
\hline \#Max Intake $\left[\mu \mathrm{g} \mathrm{kg}^{-1} \mathrm{bw} / \mathrm{d}\right]$ & 0.14 & 5.89 & 17.6 & 0.48 \\
\hline Established TDI [ $\left.\mu \mathrm{g} \mathrm{kg}^{-1} \mathrm{bw} / \mathrm{d}\right]$ & None defined & 2 & 1 & 0.25 \\
\hline \#Individuals Exceeding TDI & $\mathrm{n} / \mathrm{a}$ & $4 / 89$ & $1 / 89$ & $2 / 89$ \\
\hline \multicolumn{5}{|c|}{ 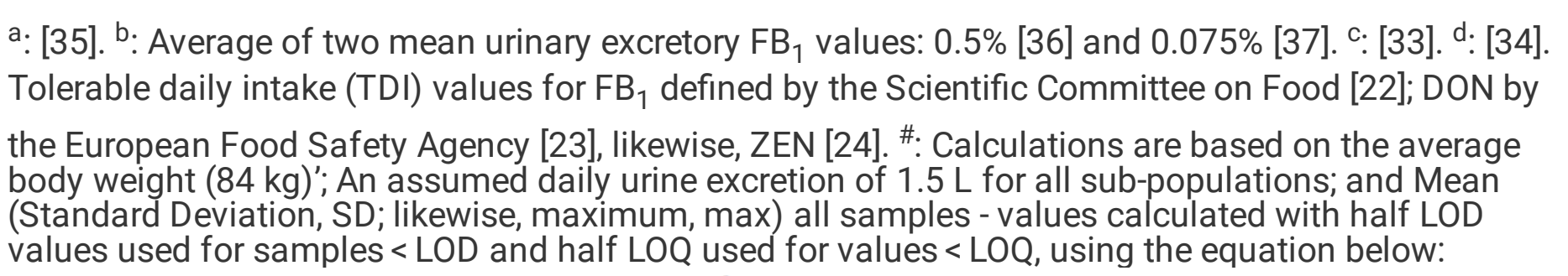 } \\
\hline $\begin{array}{c}\text { Mean (or Maximum) } \\
\begin{array}{c}\text { Estim ated Ex posure } \\
\left(\mu \mathrm{g} \mathrm{kg}^{-1} \mathrm{bw} / \text { day) }\right.\end{array}\end{array}=\frac{100 \mathrm{x} \text { (Mean m yc }}{\text { (Mean urinary ex }}$ & \multicolumn{4}{|c|}{ (Mean urinary ex cretory rate in \%) $\mathrm{x}$ (Mean body weight of $89 \mathrm{adults}$ in $\mathrm{kg}$ ) } \\
\hline
\end{tabular}

\section{Discussion}

Several studies have reported mixtures of mycotoxins in dietary staples in Cameroon $[7,26,27]$. Human biomonitoring (HBM) typically provides more reliable exposure estimates, and as such improve studies assessing the relationships between dietary mycotoxins and human health. The aim of this study was to determine the levels of urinary biomarkers of mycotoxin exposures in male and female adults in the city of Yaounde, Centre Region, Cameroon.

This study supports recent observations of frequent mycotoxin co-exposures in African populations based on urinary measures. This study observed 11 mycotoxin analytes, in 89 urine samples, while earlier studies in Nigeria, Cameroon, South Africa and Cameroon reported eight, eleven, four and seven mycotoxin analytes, respectively $[38,30,39,28]$, in roughly similar sized studies. The mean (maximum) 
concentration of $\mathrm{AFM}_{1}\left[0.03(0.21) \mathrm{\mu g} \mathrm{L}^{-1} ; 42 \%\right]$ in urine analysed in the present study was similar, albeit lower, compared with the mean (maximum) levels of $A F M_{1}$ previously reported in adult urine from Cameroon [0.05 (1.38) $\mathrm{\mu g} \mathrm{L}^{-1} ; 10 \%$ [ [30] and urine from households in Nigeria [0.3 (1.5) $\mu \mathrm{g} \mathrm{L}^{-1} ; 14.2 \%$ [38]; however, the $A F M_{1}$ incidence was higher in our present study than in the two previous reports. The $\mathrm{FB}_{1}$ concentrations were also similar in the present study (mean $\left.0.43(\max 0.83) \mu \mathrm{g} \mathrm{L}^{-1}, 10 \%\right)$ compared to (mean 0.33 ( $\max 9.54) \mathrm{\mu g} \mathrm{L}^{-1}, 3 \%$ ) previously reported in Cameroon [30], though the maximum level was somewhat higher. The detected mean (maximum) amounts of $\mathrm{FB}_{1}$ in our study were, however, lower than the mean (maximum) levels of $\mathrm{FB}_{1}\left[4.6(12.8) \mathrm{\mu g} \mathrm{L}^{-1} ; 13.3 \%\right.$ ] reported in a Nigerian population [38]. These differences should not be over-interpreted given the relatively small numbers of samples involved.

DON (and its derivative DOM-1), ZEN (and its metabolites: $a-Z E L$ and $\beta-Z E L$ ) and OTA were detected in urine, typically at higher frequencies than $\mathrm{AFM}_{1}$ and $\mathrm{FB}_{1}$. Total DON was detected about twice as frequently (76\%) in this study compared to an earlier Cameroon study [30], and much more frequently than in Nigeria (5\%), where children rather than adults dominated the exposure [38]. In South Africa, a similar high frequency $(100 \%)$ of total DON was reported as observed in the current study [39]. In these earlier studies, the mean concentrations were typically around $5-15 \mathrm{ug} \mathrm{L}^{-1}$, and this is in line with many studies in regions outside of Africa $[40,41]$. However, while the mean $\left[17.8 \mathrm{~g} \mathrm{~L}^{-1}\right]$ is similar, one individual sample $\left[760 \mathrm{~g} \mathrm{~L}^{-1}\right]$ was notably higher in the current study than most previously reported HBM studies. Notwithstanding, the major metabolite of DON in human urine, DON-15-glucuronide [42, 34] was not measured directly in this study as enzymatic deconjugation was applied [32].

The mean (maximum) concentration of OTA and ZEN were relatively lower in this study compared to previously reported data from Cameroon [30] and Nigeria [38]. However, the extremely high detection rate of $82 \%$ for total ZEN is somehow worrisome given the high xenoestrogenic potential of ZEN and its phase I biotransformation products [43]. Recent studies further highlighted that ZEN is prone to synergistic mixture effects $[44,45]$ and able to pass the placental barrier and thus exposure of mothers is likely to result in in utero exposure of the unborn child [46]. The impact of this chronic low-dose exposures on the endocrine system and related disease should be investigated in future studies.

The mean NIV level recently reported in a Nigerian study [32] was approximately 10 times greater than the level reported here for the Cameroonian population. Urinary CIT and its metabolite, DHC, were quantified in this study for the first time in Cameroon. The detected mean (maximum) concentration of total CIT [2.3 (98) $\mu \mathrm{g} \mathrm{L}^{-1} ; 80 \%$ in this present study were lower than those in Nigeria [6.0 (241) $\left.\mathrm{Mg} \mathrm{L}^{-1} ; 66 \%\right]$ [32], although our study had higher incidence. Comparison of urinary mycotoxin concentrations by either sex, or by hypertensive status did not reveal any significant differences $(p<0.05)$, noting limited study size would preclude meaningful comparisons.

One urine sample contained only one mycotoxin, while 20 combinations of two or up to seven mycotoxin urinary biomarkers were observed; more than $70 \%$ of the urines contained five or more different mycotoxins. Complex mixture toxicology remains poorly examined though several groups have recently 
examined combined effects in vitro $[47,48,49,50,51,52,53,54,55,56,57,44,45]$, with animal studies being more limited $[58,59]$. These studies remain hard to interpret for public health decisions, but some suggest more than additive effects, thus the mixtures reported here and elsewhere highlight significant knowledge gaps. It will be important to conduct longitudinal studies to better understand typical patterns and seasonal variation to better inform our understanding of mixture exposures. An interesting example for such longitudinal mycotoxin co-exposure assessment was recently published for an infant that was exclusively fed by breastmilk, which was tested for 29 mycotoxins [60]. However, it will be even more relevant to consider other food- and environment-related exposures beyond mycotoxins as proposed by the exposome concept $[61,62,63]$.

From the mean (maximum) levels of some of the major urinary mycotoxins in this present study, an estimated average dietary exposure was calculated on the basis of each participant's estimated dietary exposure using each participant's urine mycotoxin exposure amount, individual weight, an assumed $1.5 \mathrm{~L}$ urinary output per day and estimated urine excretion rate for each mycotoxin. For data with urinary concentration below the LOQ, either half the LOQ or half the LOD was used. This is generally used in food safety risk assessment (e.g. by European Food Safety Agency, EFSA) as it provides conservative estimates for calculation of exposure assessment [64]. Any dietary $\mathrm{AFM}_{1}$ is considered to be of concern, as no exposure level of $\mathrm{AFM}_{1}$ is tolerated based on the conclusions of the Scientific Committee on Food $[65,22]$. For $\mathrm{FB}_{1}, \mathrm{DON}$ and $\mathrm{ZEN}$ the mean estimated intakes were all less than the TDIs, suggesting modest exposures occurred for most. However, in this limited study, seven individuals (i.e. 8\%) of the study population exceeded one of the TDIs. For $\mathrm{FB}_{1}, 4 / 89$ (4.49\%) individuals had estimated intakes above the TDI (range: $2.3-5.9 \mu \mathrm{g} \mathrm{kg}^{-1} \mathrm{bw} / \mathrm{d}$ ). Based on food measures and urinary markers, aflatoxin and fumonisin exposure remain a significant concern in sub-Saharan Africa including Cameroon $[7,26$, $30,27,28,32,66]$. In this study co-exposures to $\mathrm{AFM}_{1}$ and $\mathrm{FB}_{1}$ occurred in about $10 \%$ of samples. For DON, only one individual exceeded the $1.0 \mu \mathrm{g} \mathrm{kg}^{-1} \mathrm{bw} / \mathrm{d}$ TDI [23], however, this intake estimate by far exceeded data typically seen in Sub-Saharan Africa at $17.6 \mu \mathrm{g} \mathrm{kg}^{-1} \mathrm{bw} / \mathrm{d}$ and is relatively higher than the previously reported study from Cameroon [30]. Likewise, the TDI of ZEN fixed by the European Food Safety Agency [24] was exceeded by the estimated maximum exposure level for total ZEN in urine samples from two individuals ( 0.30 and $0.48 \mu \mathrm{g} \mathrm{kg}^{-1} \mathrm{bw} / \mathrm{d}$ ). Overall, although only few individuals exceeded TDIs for $\mathrm{FB}_{1}, \mathrm{DON}$ and ZEN, several percent of the study population were not insignificant [30].

\section{Conclusion}

This study has further revealed that mycotoxin exposure is prevalent in city of Yaounde, Centre Region, Cameroon. This is evident by the detection of 11 mycotoxins (seven mycotoxins representative of AF, FB, DON, ZEN, NIV, OTA and CIT, and four of their derivatives: $\alpha / \beta$ ZEL, DOM-1 and DHC) in 89 adult urines in this region. Most importantly is that every single urine sample contained at least one mycotoxin. For the first time urinary CIT and its metabolite, DHC, were quantified in urine samples from Cameroon. The coexistence of as much as seven mycotoxins in up to 20 different patterns worsens the scenario and predicts potential health risk for the population. The presence of aflatoxin biomarkers in $42 \%$ of samples 
and of those about a quarter additionally contained fumonisin $B_{1}$ is a concern. The potential risk derived from additional mixture effects remains poorly defined, but as further studies add to these data sets their putative contributions may be understood, while aflatoxins and fumonisins remain a priority in populations such as Cameroon with a high incidence of liver disease $[67,68,69]$ and stunting $[70,71]$.

\section{Abbreviations}

$\mathrm{LC} / \mathrm{MS} / \mathrm{MS}$

Liquid Chromatography tandem mass spectrometry

MTLs

Maximum tolerable limits

AFs

aflatoxins

$\mathrm{AFB}_{1}$

aflatoxin $B_{1}$

total AFs

total aflatoxins

FBs

fumonisins

$\mathrm{FB}_{1}$

fumonisin $B_{1}$

total FBs

total fumonisins

DON

deoxynivalenol

DOM-1

deepoxy-DON

OTA

ochratoxin A

ZEN

zearalenone

a-ZEL

alpha-zearalenol

$\beta$-ZEL

beta-zearalenol

NIV

nivalenol

CIT

citrinin

DHC 
Dihydrocitrinone

$\mathrm{AOH}$

alternariol

TDI

Tolerable daily intake

BMI

body mass index

$\mathrm{MeOH}$

Methanol

LC

Liquid chromatography

CAN

acetonitrile

$\mathrm{HAc}$

glacial acetic acid

MS

Mass spectrometry

ACN $/ \mathrm{H}_{2} \mathrm{O}$

acetonitrile/water

LC-ESI-MS/MS

liquid chromatography-electrospray ionization-tandem mass spectrometry

ESI

electro spray ionization (ESI)

UHPLC

Ultra-high performance liquid chromatography

UMBs

urinary mycotoxins biomarkers

sMRM

scheduled multiple reaction monitoring

LOD

limit of detection

LOQ

limit of quantitation

SD

Standard Deviation

IQR

Interquartile range

Max

Maximum

$\%$ 
Percentage

nd

Not detected

HBM

Human biomonitoring

EFSA

European Food Safety Agency

\section{Declarations}

\section{Ethics approval and consent to participate}

Ethical approval was received from the Cameroon National Ethics Committee of Research for Human Health (Authorisation No. 2013/05/252/CNERSH/SP). Signed informed consent forms were obtained from 89 adult male $(n=39)$ and female $(n=50)$ volunteers (age range: $28-85$ years, body weight (range: $55-129 \mathrm{~kg})$ ) recruited in this study.

\section{Consent for publication}

Not applicable.

\section{Availability of data and material}

All data generated or analysed during this study are included in this published article [and its supplementary information files].

\section{Competing interests}

The authors declare they have no competing financial interests.

\section{Funding}

The study was partly funded by the Research Modernization Allowance to lecturers of the Ministry of Higher Education of Cameroon, and the City of Vienna Jubilee Funds for the University of Natural Resources and Life Sciences, Vienna (BOKU Research Funding, project MycoMarker).

\section{Authors' contributions}


DD, PFM, ANT, EYM surveyed and recruited participants. EYM managed the participants in his clinic. WAA, BS, CNE analysed urinary mycotoxin biomarkers. WAA, BS, PCT analysed and interpreted the urine data. WAA drafted the manuscript with major contributions to writing from BW, RK, CTE, BS, CNE, PFM. All authors read and approved the final manuscript.

\section{Acknowledgement}

Authors are thankful to the participants who donated urine samples. In addition, authors sincerely acknowledge the participating clinic in Yaounde Cameroon (Les Promoteurs de la Bonne Sante) where 66 hypertensive adult participants were recruited into this study. Furthermore, authors are grateful to the BOKU/IFA-Tulln, Austria, where urinary mycotoxin biomarkers and biomeasures were done.

\section{References}

1. Bennett JW, Klich M. Mycotoxins. Clin Microbiol Rev. 2013;16:497-516. doi:10.1128/CMR.16.3.497516.2003.

2. Richard JL, Payne GA. Mycotoxins in plant, animal, and human systems. Council for Agricultural Science and Technology, Task Force Report No. 139. 2003.

3. Ezekiel CN, Sulyok M, Ogara IM, Abia WA, Warth B, Sarkanj B, et al. Mycotoxins in uncooked and plate-ready household food from rural northern Nigeria. Food Chem Toxicol. 2019;128:171179.

4. Karlovsky P, Suman M, Berthiller F, Meester JD, Eisenbrand G, Perrin I, et al. Impact of food processing and detoxification treatments on mycotoxin contamination. Mycotoxin Res. 2016;32(4):179-205.

5. Lewis L, et al. Kenya Aflatoxicosis Investigation Group. Aflatoxin contamination of commercial maize products during an outbreak of acute aflatoxicosis in eastern and central Kenya. Environ Health Perspect. 2005;113:1763-7.

6. IARC (International Agency for the Research on Cancer). Some traditional herbal medicines, some mycotoxins, naphthalene and styrene. IARC Monographs on the evaluation of carcinogenic risks to humans. 2002;82:1-556.

7. Tchana NA, Moundipa PF, Tchouanguep FM. Aflatoxin contamination in food and body fluids in relation to malnutrition and cancer status in Cameroon. Int J Environ Res Publ Health. 2010;7:17888.

8. IARC (International Agency for Research on Cancer). Improving Public Health through Mycotoxin Control. IARC Scientific Publication No. 158. Edited by Pitt JI, Wild CP, Baan RA, Gelderblom WCA, Miller JD, Riley RT, Wu F. 2012; ISBN-13:978-92-832-2158-6\$4.

9. Kimanya ME, Meulenaer BD, Baert K, Tiisekwa B, Camp JV, Samapundo S, et al. Fumonisin exposure through maize in complementary foods is inversely associated with linear growth of infants in Tanzania. Mol Nutr Food Res. 2010;54:1659-67. https://doi.org/10.1002/mnfr.200900483. PMID: 20521269. 
10. Turner PC. The molecular epidemiology of chronic aflatoxin driven impaired child growth. Scientifica. 2013;152879:19.

11. Bondy GS, Pestka JJ. Immunomodulation by Fungal Toxins. J Toxicol Environ Health B Crit Rev. 2000;3(2):109-43. doi:10.1080/109374000281113.

12. Pestka JJ, Zhou HR, Moon Y, Chung YJ. Cellular and molecular mechanisms for immune modulation by deoxynivalenol and other trichothecenes: unraveling a paradox. Toxicol Lett. 2004;153:61-73.

13. Pestka JJ, Deoxynivalenol. Mechanisms of action, human exposure, and toxicological relevance. Arch Toxicol. 2010;84:663-79. doi:10.1007/s00204-010-0579-8.

14. Pierron A, Alassane-Kpembi I, Oswald IP. Impact of Mycotoxin on Immune Response and Consequences for Pig Health. Anim Nutr. 2016;2(2):63-8. doi:10.1016/j.aninu.2016.03.001.

15. Turner PC, Moore SE, Hall AJ, Prentice AM, Wild CP. Modification of immune function through exposure to dietary aflatoxin in Gambian children. Environ Health Perspect. 2003;111:217-20.

16. Marasas WF, Riley RT, Hendricks KA, Stevens VL, Sadler TW, Gelineau-van WJ, et al. Fumonisins disrupt sphingolipid metabolism, folate transport, and neural tube development in embryo culture and in vivo: a potential risk factor for human neural tube defects among populations consuming fumonisin-contaminated maize. J Nutr. 2004;134(4):711-6.

17. Missmer SA, Suarez L, Felkner M, Wang E, Merrill AH Jr, Rothman KJ, et al. Exposure to fumonisins and the occurrence of neural tube defects along the Texas- Mexico border. Environ Health Perspect. 2006;114:237-41. https://doi.org/10.1289/ehp.8221. PMID: 16451860.

18. FAO (Food and Agriculture Organization). Worldwide regulations for mycotoxins in food and feed in 2003. Rome: FAO. Food and Nutrition Papers No; 2004. p. 81.

19. European Commission (EC). European Commission Regulation No 466/2001 of 8 March 2001 setting maximum levels for certain contaminants in foodstuffs. Official Journal of the European Union. 2001.

20. European Commission (EC). Commission Regulation (EC) No 1881/2006 of 19 December 2006 setting maximum levels for certain contaminants in foodstuffs (consolidated version 2010-07-01). Official Journal of the European Union. 2006.

21. Egmond HPV, Schothorst RC, Jonker MA. Regulations relating to mycotoxins in food Perspectives in a global and European context. Anal Bioanal Chem. 2007;389:147-57.

22. SCF (Scientific Committee on Food). Updated opinion of the Scientific Committee on Food on Fumonisin B1, B2 and B3: SCF/CS/CNTM/MYC/28 Final. 2003.

23. EFSA (European Food Safety Authority). Panel on Contaminants in the Food Chain (CONTAM). Scientific Opinion on the risks to human and animal health related to the presence of deoxynivalenol and its acetylated and modified forms in food and feed. EFSA Journal. 2017;15(9):4718, 345 pp. https://doi.org/ 10.2903/j.efsa.2017.4718.

24. EFSA (European Food Safety Agency). Scientific Opinion on the risks for public health related to the presence of zearalenone in food. Question Number: EFSA-Q-2010-00958. EFSA Journal. 2011;9(6):2197. doi:10.2903/j.efsa.2011.2197. 
25. Njobeh PB, Dutton MF, Koch SK, Chuturgoon AA, Stoev SD, Mosonik JS. Simultaneous occurrence of mycotoxins in human food commodities from Cameroon. Mycotox Res. 2010;26:47-57.

26. Abia WA, Warth B, Sulyok M, Krska R, Tchana A, Njobeh PB, et al. Bio-monitoring of mycotoxin exposure in Cameroon using a urinary multi-biomarker approach. Food Chem Toxicol. 2013a;62:927-34.

27. Abia WA, Warth B, Ezekiel CN, Sarkanj B, Turner PC, Marko D, et al. Uncommon toxic microbial metabolite patterns in traditionally home-processed maize dish ( $f u f u)$ consumed in rural Cameroon. Food Chem Toxicol. 2017;107:10-9.

28. Njumbe EE, Diana J, Mavungu D, Song S, Sioen I, Saeger SD. Multimycotoxin analysis in urines to assess infant exposure: A case study in Cameroon. Environ Int. 2013;57-58:50-9.

29. Nguegwouo E, Njumbe EE, Njobeh PB, Medoua GN, Ngoko Z, Fotso M, et al. Aflatoxin and Fumonisin in Corn Production Chain in Bafia, Centre Cameroon: Impact of Processing Techniques. J Pharm Pharmacol. 2017;5:579-90.

30. Abia WA, Warth B, Sulyok M, Krska R, Tchana AN, Njobeh PN, et al. Determination of multi-mycotoxin occurrence in cereals, nuts and their by-products and estimation of human dietary mycotoxin exposure in Cameroon. Food Control. 2013b;31:438-53.

31. Asam S, Konitzer K, Schieberle P, Rychlik M. Stable isotope dilution assays of alternariol and alternariol monomethyl ether in beverages. J Agric Food Chem. 2009;57:515260. doi:10.1021/jf900450w.

32. Šarkanj B, Ezekiel CN, Turner PC, Abia WA, Rychlik M, Krska R, et al. Ultra-sensitive, stable isotope assisted quantification of multiple urinary mycotoxin exposure biomarkers. Anal Chim Acta. 2018;1019:84-92.

33. Turner PC, White KLM, Burley VJ, Hopton RP, Rajendram A, Fisher J, et al. A comparison of deoxynivalenol intake and urinary deoxynivalenol in UK adults. Biomarkers. 2010;15:553-62. doi:10.3109/1354750X.2010.495787.

34. Warth B, Sulyok M, Berthiller F, Schuhmacher R, Krska R. New insights into the human metabolism of the Fusarium mycotoxins deoxynivalenol and zearalenone. Toxicol Lett. 2013;220(1):88-94. https://doi.org/10.1016/j.toxlet.2013.04.012.

35. Zhu JQ, Zhang LS, Hu X, Xiao Y, Chen JS, Xu YC, et al. Correlation of dietary aflatoxin B 1 levels with excretion of aflatoxin M1 in human urine. Cancer Res. 1987;47:1848-52.

36. Riley RT, Torres O, Showker JL, Zitomer NC, Matute J, Voss KA, et al. The kinetics of urinary fumonisin B1 excretion in humans consuming maize-based diets. Mol Nutr Food Res. 2012;56:1445-55.

37. van der Westhuizen L, Shephard GS, Burger HM, Rheeder JP, Gelderblom WGA, Wild CP, et al. Fumonisin B 1 as a urinary biomarker of exposure in a maize intervention study among South African subsistence farmers. Cancer Epidemiol Biomar. 2011;20:483-9.

38. Ezekiel CN, Warth B, Ogara IM, Abia WA, Ezekiel VC, Atehnkeng J, et al. Mycotoxin exposure in rural residents in northern Nigeria: a pilot study using multi-urinary biomarkers. Environ Int. 2014;66:138- 
45.

39. Shephard GS, Burger HM, Gambacorta L, Gong YY, Krska R, Rheeder JP, et al. Multiple mycotoxin exposure determined by urinary biomarkers in rural subsistence farmers in the former Transkei, South Africa. Food Chem Toxicol. 2013;62:217-25. https://doi.org/10.1016/j.fct.2013.08.040.

40. Turner PC, Flannary B, Issit K, Ali M, Pestka J. The role of biomarkers in evaluating human health concerns from fungal contaminants in food. Nutrition Res Rev. 2012;25:162-79.

41. Šarkanj B, Warth B, Uhlig S, Abia WA, Sulyok M, Klapec T, et al. Urinary analysis reveals high deoxynivalenol exposure in pregnant women from Croatia. Food Chem Toxicol. 2013;62:231-7.

42. Warth B, Sulyok M, Fruhmann P, Berthiller F, Schuhmacher R, Hametner C, et al. Assessment of human deoxynivalenol exposure using an LC-MS/MS based biomarker method. Toxicol Lett. 2012a;211(1):85-90. doi:10.1016/j.toxlet.2012.02.023.

43. Preindl K, Braun D, Aichinger G, Sieri S, Fang M, Marko D, et al. A Generic Liquid Chromatography Tandem Mass Spectrometry Exposome Method for the Determination of Xenoestrogens in Biological Matrices. Anal Chem. 2019;91(17):11334-42. DOI:10.1021/acs.analchem.9b02446.

44. Vejdovszky K, Hahn K, Braun D, Warth B, Marko D. Synergistic estrogenic effects of Fusarium and Alternaria mycotoxins in vitro. Arch Toxicol. 2017a;91(3):1447-60. DOI:10.1007/s00204-016-1795-7.

45. Vejdovszky K, Schmidt V, Warth B, Marko D. Combinatory estrogenic effects between the isoflavone genistein and the mycotoxins zearalenone and alternariol in vitro. Mol Nutr Food Res. 2017b;61:1600526. DOI:10.1002/mnfr.201600526.

46. Warth B, Preind K, Manser P, Wick P, Marko D, Buerki-Thurnherr T. Transfer and Metabolism of the Xenoestrogen Zearalenone in Human Perfused Placenta. Environ Health Perspect. 2019;127(10):107004. DOI:10.1289/EHP4860.

47. Assunção R, Pinhão M, Loureiro S, Alvito P, Silva MJ. A multi-endpoint approach to the combined toxic effects of patulin and ochratoxin a in human intestinal cells. Toxicol Lett. 2019;313:120-9.

48. Eze UA, Huntriss JD, Routledge MN, Gong YY. In vitro effects of single and binary mixtures of regulated mycotoxins and persistent organochloride pesticides on steroid hormone production in MA-10 Leydig cell line. Toxicol In Vitro. 2019;60:272-80.

49. Fernández-Blanco C, Elmo L, Waldner T, Ruiz MJ. Cytotoxic effects induced by patulin, deoxynivalenol and toxin T2 individually and in combination in hepatic cells (HepG2). Food Chem Toxicol. 2018;120:12-23.

50. Gong L, Zhu H, Li T, Ming G, Duan X, Wang J, et al. Molecular signatures of cytotoxic effects in human embryonic kidney 293 cells treated with single and mixture of ochratoxin A and citrinin. Food Chem Toxicol. 2019;123:374-84.

51. Kouadio JH, Dano SD, Moukha S, Mobio TA, Creppy EE. Effects of combinations of Fusarium mycotoxins on the inhibition of macromolecular synthesis, malondialdehyde levels, DNA methylation and fragmentation, and viability in Caco-2 cells. Toxicon. 2007;49(3):306-17.

52. Lin X, Shao W, Yu F, Xing K, Liu H, Zhang F, et al. Individual and combined toxicity of T-2 toxin and deoxynivalenol on human C-28/I2 and rat primary chondrocytes. J Appl Toxicol. 2019;39(2):343-53. 
53. Marin DE, Pistol GC, Bulgaru CV, Taranu I. Cytotoxic and inflammatory effects of individual and combined exposure of HepG2 cells to zearalenone and its metabolites. Naunyn Schmiedebergs Arch Pharmacol. 2019;392(8):937-47.

54. Wan LYM, Woo JCS, Turner PC, Wan JMF, El-Nezami H. Individual and combined effects of Fusarium toxins on the mRNA expression of pro-inflammatory cytokines in swine jejunal epithelial cells. Toxicol Lett. 2013a;220:238-46.

55. Wan LYM, Turner PC, El-Nezami H. Individual and combined cytotoxic effects of Fusarium toxins (deoxynivalenol, nivalenol, zearalenone and fumonisins B1) on swine jejunal epithelial cells. Food Chem Toxicol. 2013b;57:276-83.

56. Wan LYM, Woo JCS, Allen K, Turner PC, El-Nezami H. Modulation of porcine $\beta$-defensins 1 and 2 upon individual and combined Fusarium toxin exposure in a swine jejunal epithelial cell line. Appl Environ Microbiol. 2013c;79:2225-32. doi:10.1128/AEM.03277-12. PMC3623212.

57. Wan ML, Allen KJ, Turner PC, El-Nezami H. Modulation of mucin mRNA (MUC5AC and MUC5B) expression and protein production and secretion in Caco-2/HT29-MTX co-cultures following exposure to individual and combined Fusarium mycotoxins. Toxicol Sci. 2014;139:83-98.

58. 10.3390/toxins 10040148

Przybylska-Gornowicz B, Lewczuk B, Prusik M, Hanuszewska M, Petrusewicz-Kosińska M, Gajęcka M, et al. The Effects of Deoxynivalenol and Zearalenone on the Pig Large Intestine. A Light and Electron Microscopy Study. Toxins (Basel). 2018;4;10(4). pii: E148. doi: 10.3390/toxins10040148.

59. Wan ML, Turner PC, El-Nezami H. Lactobacillus rhamnosus GG modulates intestinal mucosal barrier and inflammation in mice following combined dietary exposure to deoxynivalenol and zearalenone. J Functional Foods. 2016;22:34-43.

60. Braun D, Schernhammer E, Marko D, Warth B. Longitudinal assessment of mycotoxin co-exposures in exclusively breastfed infants. Cold Spring Harbor Laboratory (CSH). bioRxiv: The preprint server for biology. 2020. doi: https://doi.org/10.1101/2020.03.27.011072.

61. Wild CP. Complementing the genome with an "exposome": the outstanding challenge of environmental exposure measurement in molecular epidemiology. Cancer Epidemiol Biomarkers Prev. 2005;14(8):1847-50. DOI:10.1158/1055-9965.EPI-05-0456.

62. Warth B, Spangler S, Fang M. Exposome-Scale Investigations Guided by Global Metabolomics, Pathway Analysis, and Cognitive Computing. Anal Chem. 2017;89(21):11505-13. DOI:10.1021/acs.analchem.7b02759.

63. Vermeulen R, Schymanski EL, Barabási A, Miller GW. The exposome and health: Where chemistry meets biology. Science. 2020;367(6476):392-6. DOI:10.1126/science.aay3164.

64. EFSA (European Food Safety Authority). Management of left-censored data in dietary exposure assessment of chemical substances. EFSA Journal. 2010;8(3):1557. doi:10.2903/j.efsa.2010.1557.

65. SCF (Scientific Committee on Food). Opinion of the Scientific Committee on Food on Fusarium toxins. In: Part 6: Group Evaluation of T-2 Toxin, HT-2 Toxin. Nivalenol: SCF/CS/CNTM/MYC/27 Final; 2002. 
66. Warth B, Sulyok M, Fruhmann P, Mikula H, Berthiller F, Schuhmacher R, et al. Development and validation of a rapid multi-biomarker LC-MS/MS method to assess human exposure to mycotoxins. Rapid Commun Mass Spectr. 2012b;26:1533-40.

67. Ankouane A, Noah N, Hell M, et al. Hepatocellular carcinoma in Cameroon: epidemiology and risk factors. J Appl Med Sci. 2014;3(2):27-33.

68. Bigna JJ, Amougou MA, Asangbeh SL. Kenne AM, Noumegni SRN, Ngo-Malabo ET, et al. Seroprevalence of hepatitis B virus infection in Cameroon: a systematic review and meta-analysis. BMJ Open 2017;7:e015298. doi:10.1136/bmjopen-2016-015298.

69. Djuidje NM, Fepa KAG, Nwobegahay J, Moundipa FP. HBV and HCV Seroprevalence and the Predominant HCV Genotypes in a Hospital Setting in Cameroon. Virol Mycol. 2018;7:178. doi:10.4172/2161-0517.1000178.

70. Nzefa LD, Monebenimp F, Äng C. Undernutrition among children under five in the Bandja village of Cameroon, Africa, South African. Journal of Clinical Nutrition. 2019;32(2):46-50.

DOI:10.1080/16070658.2018.1448503.

71. UNICEF/WHO/WB (United Nations Children Fund/World Health Organization/World Bank). Prevalence of stunting, height for age (\% of children under 5) - Cameroon. UNICEF, WHO, World Bank: Joint child malnutrition estimates (JME). Aggregation is based on UNICEF, WHO, and the World Bank harmonized dataset (adjusted, comparable data) and methodology. 2019. Available online and assessed on 02.04.2020 at 03:36 at: https://data.worldbank.org/indicator/SH.STA.STNT.ZS? locations $=\mathrm{CM}$.

\section{Supplementary Files}

This is a list of supplementary files associated with this preprint. Click to download.

- Supplementarytable1.docx 